\title{
Trafficking of a Ligand-Receptor Complex on the Growth Cones as an Essential Step for the Uptake of Nerve Growth Factor at the Distal End of the Axon: A Single-Molecule Analysis
}

\author{
Tomomi Tani, ${ }^{1}$ Yoshikazu Miyamoto, ${ }^{2}$ Kazuhiro E. Fujimori, ${ }^{3}$ Takahisa Taguchi, ${ }^{3}$ Toshio Yanagida, ${ }^{2,5}$ Yasushi Sako, \\ and Yoshie Harada ${ }^{1,5}$ \\ ${ }^{1}$ Tokyo Metropolitan Institute of Medical Science, Tokyo 113-8613, Japan, ${ }^{2}$ Graduate School of Frontier Biosciences, Osaka University, Osaka 565-0871, \\ Japan, ${ }^{3}$ Cell Engineering Research Institute, Advanced Industrial Science and Technology, Ikeda 563-8577, Japan, and 4 Precursory Research for Embryonic \\ Science and Technology, and ${ }^{5}$ Core Research for Evolutional Science and Technology, Japan Science and Technology Agency, Saitama 332-0012, Japan
}

\begin{abstract}
The behavior of single molecules of neurotrophins on growth cones was observed by the use of the fluorescent conjugate of nerve growth factor (NGF), Cy3-NGF. After the application of $0.4 \mathrm{~nm}$ Cy3-NGF, chick dorsal root ganglion growth cones responded within 1 min of adding the stimulus by expanding their lamellipodia. Only 40 molecules of Cy3-NGF, which occupied $<5 \%$ of the estimated total binding sites on a single growth cone, were required to initiate the motile responses. After binding to the high-affinity receptor, Cy3-NGF displayed lateral diffusion on the membrane of the growth cones with a diffusion constant of $0.3 \mu \mathrm{m}^{2} \mathrm{~s}^{-1}$. The behavior of Cy3-NGF was shifted to a one-directional rearward movement toward the central region of the growth cone. The one-directional movement of Cy3-NGF displayed the same rate as the rearward flow of actin, $\sim 4 \mu \mathrm{m} / \mathrm{min}$. This movement could be stopped by the application of the potent inhibitor of actin polymerization, latrunculin B. Molecules of Cy3-NGF were suggested to be internalized in the vicinity of the central region of the growth cone during this rearward trafficking, because Cy3-NGF remained in the growth cone after the growth cones had been exposed to an acidic surrounding medium: acidic medium causes the complete dissociation of Cy3-NGF from the receptors on the surface of growth cones. These results suggested that actin-driven trafficking of the NGF receptor complex is an essential step for the accumulation and endocytosis of NGF at the growth cone and for the retrograde transport of NGF toward the cell body.
\end{abstract}

Key words: nerve growth factor; growth cone; dorsal root ganglion; fluorescent single-molecule imaging; rearward actin flow; endocytosis

\section{Introduction}

The growth cone is a motile structure located at the distal tip of the nerve fiber (Nakai and Kawasaki, 1959). During embryogenesis, the growth cone serves to guide the nerve fiber to an appropriate target through the aid of guidance cues and neurotrophins (Tessier-Lavigne and Goodman, 1996). The 2.5S nerve growth factor (NGF), the founding member of neurotrophins, is a secreted protein composed of two identical $13 \mathrm{kDa} \beta$-subunits (Levi-Montalcini, 1982). NGF promotes the axonal growth of sensory and sympathetic neurons. After application of NGF, the growth cones of these neurons respond to the stimulus by expanding their lamellipodia (Connolly et al., 1987). This motile

\footnotetext{
Received Nov. 7, 2004; revised Jan. 5, 2005; accepted Jan. 6, 2005.

This work was supported by a grant-in-aid for Scientific Research from the Japan Society for the Promotion of Science and the Basic Research Programs of the Japan Science and Technology Agency. We thank Dr. Masahiro Ueda for his suggestion of introducing single molecule detection techniques for the study of the growth cone, Dr. Tetsuichi Wazawa for his advice on the synthesis of fluorescent conjugates, and Dr. Richard D. Allen for his critical reading of this manuscript.

Correspondence should be addressed to Tomomi Tani, The Tokyo Metropolitan Institute of Medical Science, Honkomagome 3-18-22, Bunkyo-ku, Tokyo 113-8613, Japan. E-mail: ttani@rinshoken.or.jp.

DOI:10.1523/JNEUROSCI.4570-04.2005

Copyright $\odot 2005$ Society for Neuroscience $\quad$ 0270-6474/05/252181-11\$15.00/0
}

response leads to an acceleration of the forward progress of the growth cones, together with the signaling cascades for the assembly of microtubules at the growth cone (Zhou et al., 2004). In addition to the axon elongation of sensory and sympathetic nerve cells, NGF affects the survival of these neurons by reacting with the distal tip of their axons (i.e., at their growth cones) (Campenot, 1977). After binding, NGF and the receptor complex was endocytosed, trafficked to signaling endosomes (Grimes et al., 1997; Delcroix et al., 2003), and retrogradely transported to the cell bodies (Hendry et al., 1974); however, the issue of whether the retrograde signal from NGF requires the axonal transport of NGF is still contentious, because an application of NGF covalently cross-linked to beads supplied to the distal axons results in the survival of sympathetic neurons without the retrograde transport of the NGF (MacInnis and Campenot, 2002).

The binding and the subsequent internalization of NGF by sensory neurons and other NGF-responsive cells has been studied in the past by the use of ${ }^{125}$ I-labeled NGF (Herrup and Shooter, 1973; Sutter et al., 1979; Chao et al., 1986; Hempstead et al., 1991; Kaplan et al., 1991). Fluorescently labeled NGF has been used to investigate the mobility and clustering of NGF (Levi et al., 1980), kinetic analyses of NGF-receptor interactions (Kasaian et 
al., 1994), and more recently, endocytosis and retrograde transport of NGF along axons (Gatzinsky et al., 2001; Lalli and Schiavo, 2002; Bronfman et al., 2003). Most of these studies failed to focus on the interaction of NGF with the growth cones at the distal ends of axons, although the major site for the uptake of neurotrophins had been thought to be located at the distal tips of nerve fibers (Korsching and Thoenen, 1983). Here we were able to observe the behavior of single molecules of NGF on the growth cone of dorsal root ganglion neurons by using a novel fluorescent conjugate of NGF, Cy3-NGF. Tracking NGF from its site of binding to a receptor and then to its internalization site revealed a critical role for rearward actin flow (Forscher and Smith, 1988) on the efficient uptake of NGF at the growth cone.

\section{Materials and Methods}

Cells. Dorsal root ganglia (DRG) were dissected from embryonic day 7 White Leghorn chicken embryos. The ganglia were placed on the surface of sterilized $24 \times 24 \mathrm{~mm}$ glass coverslips $(0.17 \mathrm{~mm}$ thick) in $35-\mathrm{mm}$ diameter plastic culture dishes (Asahi Technoglass, Chiba, Japan) that were filled with $1 \mathrm{ml}$ of DMEM-F-12 medium (Invitrogen, Carlsbad, CA) supplemented with 2 nм $\beta$ NGF subunit (Upstate Biotechnology, Charlottesville, VA) and SPIT mixture (Sigma-Aldrich, St. Louis, MO) containing $10 \mu \mathrm{g} / \mathrm{ml}$ insulin, $5.5 \mu \mathrm{g} / \mathrm{ml}$ transferrin, $0.005 \mu \mathrm{g} / \mathrm{ml}$ sodium selenite, and $120 \mu \mathrm{g} / \mathrm{ml}$ pyruvate. The surface of the glass coverslip had been treated with $0.1 \mathrm{mg} / \mathrm{ml}$ poly-L-lysine (Sigma-Aldrich) for $1 \mathrm{~h}$ before use. The culture dishes with DRG were then incubated in a humidified incubator at $37.6^{\circ} \mathrm{C}$. Incubation with NGF for $15 \mathrm{~h}$ allowed numerous DRG neurons to regenerate and elongate axons along the surface of the coverslip. The ganglia were then transferred to the DMEM-F-12 medium containing the SPIT mixture but without NGF. The DRG were again incubated in the same incubator for at least $8 \mathrm{~h}$ before the experiments.

For the experiments, an O-shaped hydrophobic silicone rubber sheet ( $10 \mathrm{~mm}$ inner diameter, $22 \mathrm{~mm}$ outer diameter, $1 \mathrm{~mm}$ thick) was glued to the coverslip with white Vaseline (Sigma-Aldrich) so that the ganglion was located at the center of the hole of the $\mathrm{O}$-shaped sheet, and then the coverslip was removed from the culture dish together with a small amount of culture medium $(0.1 \mathrm{ml})$. After its bottom surface was cleaned, the coverslip was placed on the mechanical stage of the microscope, and $0.9 \mathrm{ml}$ of additional culture medium without NGF was introduced onto the hydrophobic $\mathrm{O}$-shaped sheet. The temperature around the specimen was kept at $37^{\circ} \mathrm{C}$ by a temperature-controlled water circulator (HAAKE DC-30; Haake Technik, Vreden, Germany). The room temperature was kept at $33^{\circ} \mathrm{C}$ during experiments.

Synthesis of fluorescently conjugated NGF. NGF $(0.025 \mathrm{mg}$ of $2.5 \mathrm{~S})$ was dissolved in $0.1 \mathrm{ml}$ of citric acid- $\mathrm{NaOH}$ buffer, $\mathrm{pH} 4.3$, and mixed with cystamine sulfate (Nacalai Tesque, Kyoto, Japan) (final concentration, $0.3 \mathrm{M}$ ). 1-Ethyl-3-[3-dimethylaminopropyl] carbodiimide (Pierce, Rockford, IL) (final concentration, $0.3 \mathrm{~mm}$ ) and the same amount of $\mathrm{N}$-hydroxysulfosuccinimide (Pierce) were added to the solution with 2.5S NGF. The solution was incubated on ice for $2 \mathrm{~h}$. The solution was loaded onto a NAP-5 gel-filtration column equilibrated with $200 \mathrm{~mm}$ sodium phosphate buffer, $\mathrm{pH}$ 7.0, to remove free cystamine. A reducing agent, Tris(2-carboxyethyl) phosphine (Pierce) (final concentration, $0.01 \mathrm{mg} / \mathrm{ml}$ ), was added to the collected solution of cystamine-2.5S NGF and incubated at room temperature $\left(25^{\circ} \mathrm{C}\right)$ for $20-30 \mathrm{~min}$. Cy3 maleimide was synthesized by mixing $\mathrm{Cy} 3 \mathrm{~N}$-hydroxysuccinimidyl-ester (Amersham Biosciences, Piscataway, NJ) with $N$-[2-(1-piperazinyl)ethyl] maleimide (Dojindo, Kumamoto, Japan) in dimethyl sulfoxide (Wako Pure Chemical Industries, Osaka, Japan) for $24 \mathrm{~h}$ at $37^{\circ} \mathrm{C}$. Synthesized Cy3 maleimide (final concentration, $10 \mu \mathrm{M}$ ) was added to the solution with reduced cystamine-NGF (final concentration, 1-2 $\mu \mathrm{M}$ ). The reaction solution was incubated in an oxygen-free environment for $2 \mathrm{~h}$ at room temperature. After the incubation, the solution was loaded onto a NAP-5 column equilibrated with $20 \mathrm{~mm}$ sodium phosphate buffer, $\mathrm{pH}$ 7.0, to remove the free Cy3. To determine the ratio of dye to protein, absorbance of the collected fractions at 280 and $550 \mathrm{~nm}$ were measured by a spectrophotometer (DU650; Beckman Coulter, Fullerton, CA).
Microscopy. A conventional epifluorescent microscope (IX-70; Olympus, Tokyo, Japan) was modified to observe the single molecules of fluorescent NGF. The light from a $100 \mathrm{~W}$ mercury arc lamp was introduced into the back aperture of a $10 \times$ objective lens to illuminate a largediameter opening (1.2 mm) of fiber optics (ST1200I-SY; Mitsubishi Electric Cable, Tokyo, Japan), which was used as a light scrambler (Kam et al., 1993). The light from the scrambler output was focused on the field diaphragm of the epifluorescent microscope through a $4 \times$ objective lens. Optical filters and an electromagnetic shutter (Uniblitz LS6; Vincent Associates, Rochester, NY) were placed between the field diaphragm and the $4 \times$ lens. Through an objective lens $(60 \times$ PlanApo, 1.4 numerical aperture; Olympus), growth cones on a glass coverslip were exposed to the excitation light. Collected fluorescence from the growth cones was focused on the cooled CCD camera (Micromax 512BFT; Roper Scientific, Duluth, GA). DIC images of the growth cones were recorded simultaneously with fluorescent images of the growth cones by using a homemade dual-view light-splitting system (Kinosita et al., 1991).

Drug application and microinjection. Latrunculin B (Biomol, Plymouth Meeting, PA), a drug that inhibits actin polymerization, was applied to the growth cone by adding it to the bath. To introduce Alexa 647phalloidin (Molecular Probes, Eugene, OR) into the growth cone, a microinjection technique was used. A patch pipette (opening diameter, 1 $\mu \mathrm{m}$ ) was filled with $100 \mathrm{~nm}$ Alexa 647-phalloidin dissolved in the artificial intracellular solution composed of (in $\mathrm{mM}$ ): $115 \mathrm{~K}$-acetate, 25 HEPES-KOH, pH 7.4, 2 EGTA, $2.5 \mathrm{MgCl}_{2}$, 2.5 ATP, and 1 DTT. The tip of the pipette was attached to the surface of the axon $\sim 10 \mu \mathrm{m}$ away from the central region of the growth cone in the whole-cell mode of attachment, and then phalloidin was loaded into the dorsal root ganglion growth cone through the opening of the pipette by a positive pressure applied to the inside of the pipette. The volume of injected phalloidin solution was $\sim 1: 100$ of the total volume of the growth cone.

Image analyses. Digitized 16-bit TIFF images taken by the cooled CCD camera were fed into a personal computer (Endeavor Pro 1000; EpsonDirect, Tokyo, Japan). The intensity of fluorescence, position of fluorescent dots, and area of growth cones were measured by the aid of a software package, MetaVue 4.61 (Universal Imaging, Downingtown, PA). Fluorescent intensity was expressed as the number of photons detected by a single pixel of the CCD per second (photons per second), which was calculated based on the full-well capacity of electrons for each CCD pixel, bit-number, number of binning, and exposure time of the camera. Because the length of a side of a single pixel corresponded to $0.14-0.17 \mu \mathrm{m}$ on the plane of the specimen, the resolution limit was $\sim 0.31 \mu \mathrm{m}$. The intensity of single fluorescent dots was measured by averaging the values for the brightest pixel at the center of the dot and four surrounding pixels next to the brightest pixel. The sum of these fluorescent intensities covers $\sim 50 \%$ of the total intensity of a single Cy3-NGF image. The fluorescent intensity of the lamellipodial region and the central region of the growth cone was measured by averaging the intensity values for all of the pixels within the region of interest. To obtain the background fluorescent intensity, the averaged value was measured for the area in which no fluorescent NGF was bound. This background value was subtracted to obtain the final values of fluorescent intensity. Cy3-NGF showed a slow photobleaching process during the observation. The rates of photobleaching were measured for every series of experiments, which ranged from $10^{-5}$ $\mathrm{s}^{-1}$ to $10^{-4} \mathrm{~s}^{-1}$, to correct the obtained fluorescent intensities and for determining the number of fluorescent dots. These values were transferred to a graphing software package, SigmaPlot 8.0 (SPSS, Chicago, IL), for the analyses. For the simulations, Mathematica 5.0 (Wolfram Research, Champaign, IL) was used to solve the differential equations.

\section{Results}

Responses of the dorsal root ganglion growth cone after application of a novel fluorescent analog of the nerve growth factor, Cy3-NGF

A fluorescently labeled homodimer of $\beta$ NGF, Cy3-NGF, was synthesized, and its ability to stimulate the expansion of lamellipodia at the growth cones (Connolly et al., 1987) was tested. A Cy3NGF with a Cy3/ $\beta$ NGF dimer ratio ranging from 1.0 to 1.1 was 


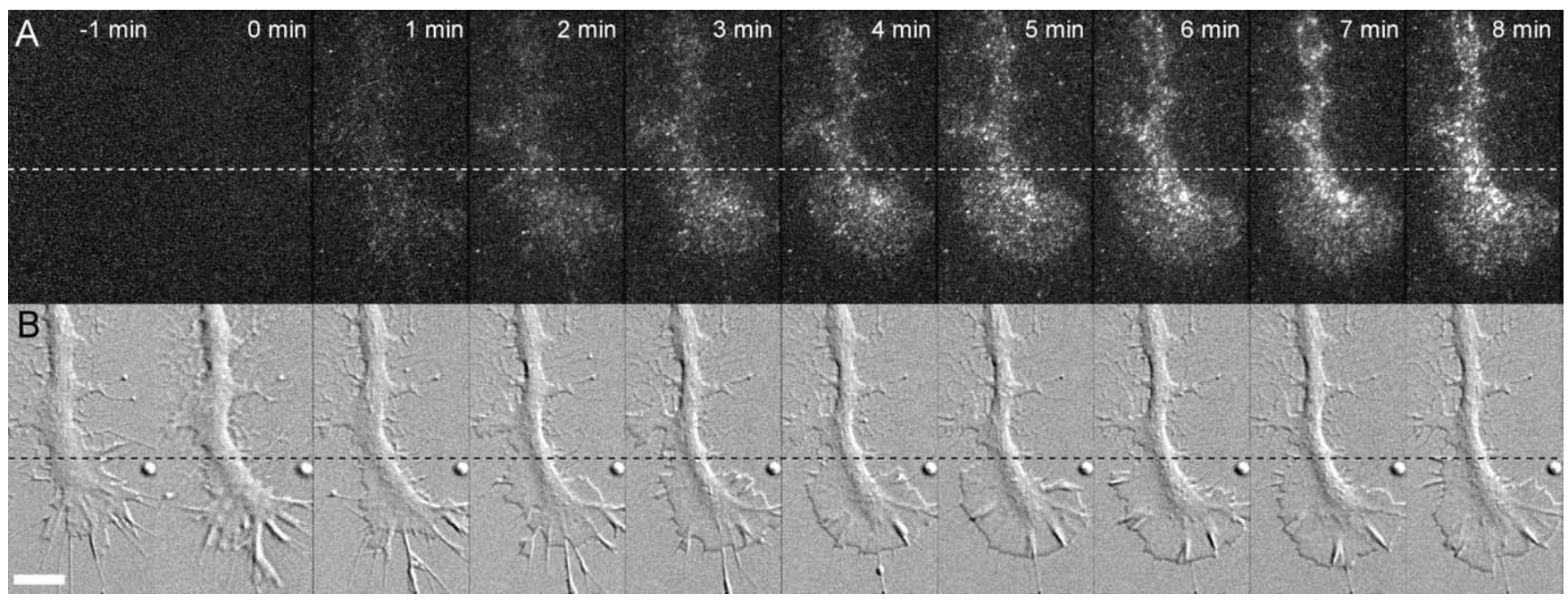

Figure 1. Responses of dorsal root ganglion growth cones on application of fluorescent nerve growth factor Cy3-NGF. Consecutive epifluorescent images $(\boldsymbol{A})$ and DIC images $(\boldsymbol{B})$ of a single dorsal root ganglion growth cone before and after the application of Cy3-NGF are shown. Cy3-NGF (final concentration, $0.4 \mathrm{~nm}$ ) was uniformly applied to the growth cone at 0 min. Images were taken with $50 \mathrm{~ms}$ exposure time without binning. Scale bar, $10 \mu \mathrm{m}$.

chosen for the experiments so that a single $\beta$ NGF dimer (2.5S NGF) possessed a single molecule of Cy3. An epifluorescent microscope with a fiber-optics excitation light scrambler (Kam et al., 1993) allowed us to see the single $\beta$ NGF dimer conjugated to Cy3, not only on the apical and basal membranes, but also within the cytoplasm of the growth cones. Figure 1 shows consecutive epifluorescent images $(A)$ and DIC images $(B)$ of a single dorsal root ganglion growth cone, simultaneously acquired before and after the application of $0.4 \mathrm{~nm}$ Cy3-NGF (supplemental movie 01, available at www.jneurosci.org as supplemental material). Before the Cy3-NGF application, there was no fluorescence observed on the growth cone. After the application of Cy3-NGF, fluorescent dots started to bind uniformly on the surface of the growth cone (Fig. 1A) $(t=1-2 \mathrm{~min})$. In the subsequent images (Fig. 1A) $(t=$ 3-8 $\mathrm{min}$ ), a gradual increase in fluorescent intensity at the lamellipodial region was followed by the accumulation of fluorescent clusters at the central region. Figure $1 B$ shows the motile responses of a single dorsal root ganglion growth cone. Before the Cy3-NGF application, the growth cone extended $\sim 10$ filopodia. After the application of Cy3-NGF, the growth cone withdrew its filopodia and started to expand its lamellipodia (Fig. 1B) $(t=1-2$ $\min )$. The time course of lamellipodial expansion beyond the broken line drawn on Figure $1 B$ is shown in Figure $2 B$. For comparison, increases in the averaged fluorescent intensity of both the central and lamellipodial regions of the growth cone beyond the broken line drawn on Figure $1 \mathrm{~A}$ are shown in Figure $2 \mathrm{~A}$. We found that the growth cone responded to the stimulus of $\mathrm{Cy} 3-$ NGF before the Cy3-NGF clusters were formed at the central region of the growth cone. The difference between the fluorescent intensity of the central region and that of the lamellipodial region became evident $\sim 2-3$ min after the application of Cy3-NGF (Fig. $2 \mathrm{~A}$, black arrowhead), which was shortly after the start of lamellipodial expansion (Fig. $2 B$, white arrowhead).

\section{Counting the number of bound Cy3-NGF on the DRG growth cones after the application of Cy3-NGF}

Figure $3 A$ shows a DIC image (left) and a fluorescent image (right) of the DRG growth cones incubated in the medium containing $0.4 \mathrm{~nm}$ Cy3-NGF. In the fluorescent image, there were hundreds of fluorescent dots uniformly spread over the expanded lamellipodium. Also, a number of brighter fluorescent clusters were observed at the central region of the growth cone. We measured the fluorescent intensity of every dot and cluster observed on the growth cone to clarify whether the single fluorescent dots observed on the DRG growth cone each represented a single $\beta$ NGF homodimer. The obtained histogram of fluorescent intensities fit a Gaussian distribution with the highest frequency at 861 photons per second (Fig. 3B). Fluorescent dots with intensities close to this value were selected to measure the time-dependent changes in the fluorescent intensities during photobleaching. Figure $3 C$ shows an averaged time-dependent change in the fluorescent intensity of dots showing photobleaching. Because the fluorescent intensity dropped to the background level in a single step, the fluorescent dots were thought to represent single molecules of Cy3. Based on these results together with the dye/protein ratio of Cy3-NGF used for the experiments, we concluded that these single fluorescent dots on the lamellipodial region of the growth cone each represented a single $\beta$ NGF homodimer.

Imaging of fluorescent NGF enabled us to analyze the in situ kinetics of NGF and the receptor interaction on the growth cone. We counted the increasing number of fluorescent dots bound onto the growth cone after the application of $0.4 \mathrm{~nm}$ Cy3-NGF (Fig. 4A). The obtained time course fit a single exponential curve with the first-order rate constant of $1.1 \times 10^{-2} \mathrm{~s}^{-1}$. The secondorder rate constant was estimated to be $2.8 \times 10^{7} \mathrm{M}^{-1} \mathrm{~s}^{-1}$, provided the first-order rate constant was in proportion to the concentration of Cy3-NGF. The number of fluorescent dots on the growth cone was determined to be $40 \pm 5$ (mean $\pm \mathrm{SD} ; n=6)$ at the time the expansion of lamellipodia was initiated. The number reached $159 \pm 37$ (mean $\pm S D ; n=8$ ) when growth cones were incubated in the medium containing $0.4 \mathrm{~nm}$ of Cy3-NGF for 20 min. We applied various concentrations of Cy3-NGF to the growth cones and counted the number of bound fluorescent dots on the single growth cones $20 \mathrm{~min}$ after the application of Cy3NGF. The obtained numbers were averaged and shown in Figure $4 B$ to fit the curve $y=B_{\max } x /\left(K_{\mathrm{d}}+x\right)$, where $y$ is the number of bound Cy3-NGF molecules, $B_{\max }$ is the maximal number of bound Cy3-NGF molecules on a single growth cone, $K_{\mathrm{d}}$ is the dissociation constant of Cy3-NGF release from the receptor, and $x$ is the concentration of Cy3-NGF. The curve with the best fit 
A
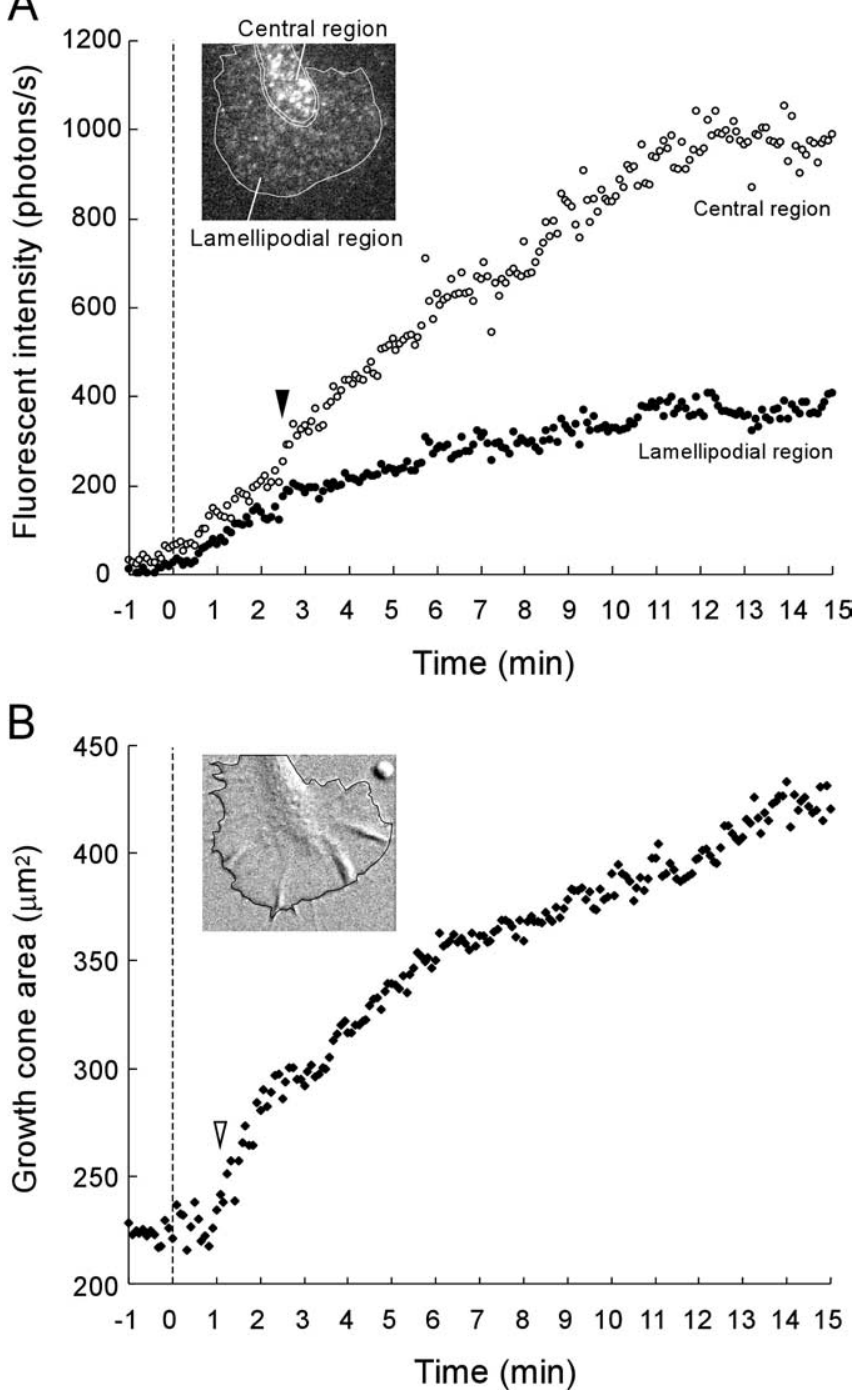

Figure 2. The time courses of Cy3-NGF binding and the evoked motile responses of the dorsal root ganglion growth cone. $A$, Time courses of the increase in the averaged fluorescent intensity measured at the central region $(O)$ and at the lamellipodial region $(\mathbf{O})$ after the application of Cy3-NGF ( $t=0 \mathrm{~min}$ ). Inset, Fluorescent micrograph of the growth cone to show the boundary lines of the central region and lamellipodial region used for the measurement. $\boldsymbol{B}$, A time course of change in the apparent area of the growth cone beyond the broken line in Figure $1 \boldsymbol{B}$. Inset, Example of a DIC micrograph to show the measured area of the growth cone (enclosed in a black line). photons/s, Photons per second.

gave 175 molecules for $B_{\max }$ and $2.7 \times 10^{-11} \mathrm{M}$ for $K_{\mathrm{d}}$. The estimated $K_{\mathrm{d}}$ was close to that of ${ }^{125} \mathrm{I}$-NGF binding to highaffinity receptors on chick sensory ganglia neurons, $2.3 \times 10^{-11}$ M (Sutter et al., 1979). These results indicated that bound fluorescent dots on the DRG growth cones incubated with Cy3-NGF at concentrations $<0.4 \mathrm{nM}$ represented the complexes of Cy3NGF with high-affinity receptors.

The number of low-affinity receptors was also estimated on a single growth cone. The density of bound fluorescent dots on the growth cone was too high to distinguish single dots when the applied concentration of Cy3-NGF was higher than $5 \mathrm{~nm}$. Instead of counting the dots, fluorescent intensities were measured on the lamellipodial region of growth cones in the medium containing various concentrations of Cy3-NGF, including the concentrations higher than $5 \mathrm{~nm}$ (Fig. 4C). The plot could be formulated as $y=\left\{B_{\max 1} x /\left(K_{\mathrm{d} 1}+x\right)\right\}+\left\{B_{\max 2} x /\left(K_{\mathrm{d} 2}+x\right)\right\}$, with two dissoci-
A

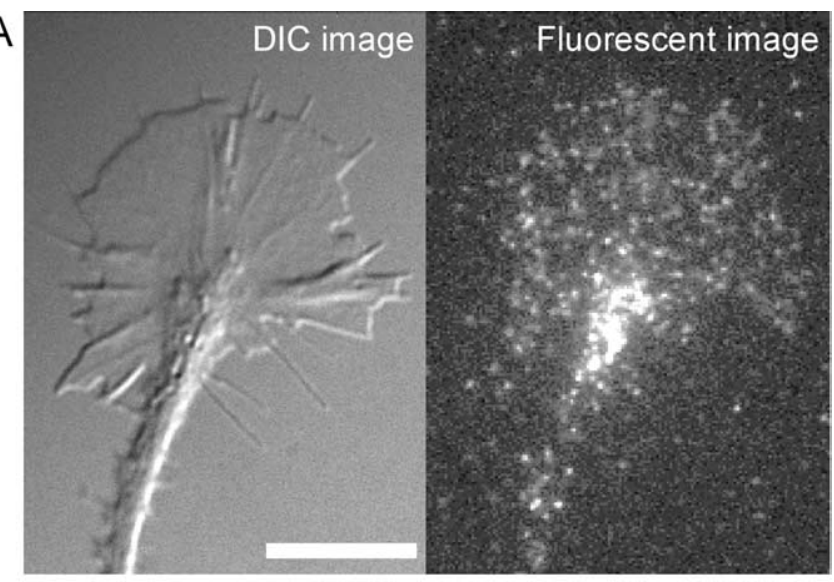

B

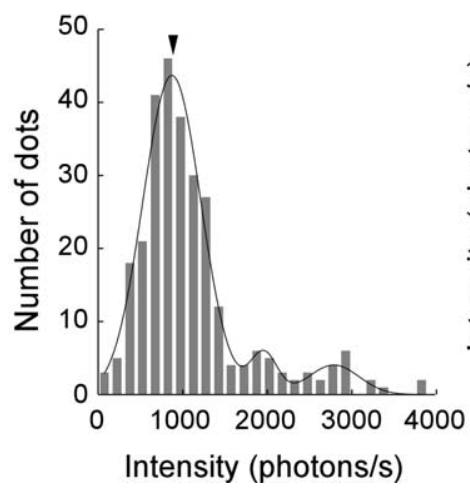

C

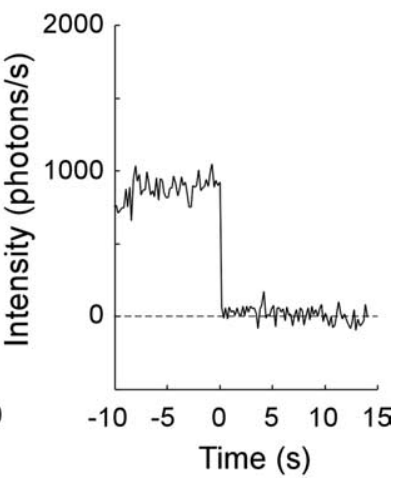

Figure 3. Fluorescent dots on the dorsal root ganglion growth cone represent the single molecules of Cy3-NGF. A, A DIC image (left) and a fluorescent image (right) of the dorsal root ganglion growth cone incubated with $0.4 \mathrm{~nm}$ Cy3-NGF for $10 \mathrm{~min}$. The fluorescent image was taken with an exposure time of $80 \mathrm{~ms}$ and $2 \times 2$ binning. Scale bar, $10 \mu \mathrm{m}$. B, Histogram of the fluorescent intensity of dots and clusters observed on the fluorescent image of a growth cone ( $n=294)$. A sum of three Gaussian curves is superimposed on the histogram. The peak, mean, and SD of Gaussian functions were fit to the graph. $C$, The photobleaching process of the single fluorescent dot on the growth cone. Timing of the data $(n=4)$ was aligned at the moment of photobleaching $(t=0 \mathrm{~s})$ to present the average of the fluorescent intensities before and after photobleaching.

ation constants, $K_{\mathrm{d} 1}=3.5 \times 10^{-11} \mathrm{M}$ and $K_{\mathrm{d} 2}=7.7 \times 10^{-9} \mathrm{M}$. The former value was close to the value, $2.7 \times 10^{-11} \mathrm{M}$, which had been obtained from single-molecule counting analyses (Fig. $4 A, B)$. The latter value was similar to that of NGF binding to low-affinity receptors (Sutter et al., 1979). The fluorescent intensity corresponding to a maximal amount of binding, $B_{\max }$ of Cy3-NGF, was 185 photons per second for high-affinity ligandreceptor interactions and was 653 photons per second for lowaffinity ligand-receptor interactions. Figure $4 C$, inset, is the correlation plot of the number of fluorescent dots on the growth cone and the fluorescent intensity measured on the same region of the growth cone. We obtained a linear regression line, $y=$ $0.916 n$ with a correlation coefficient of 0.926 , where $y$ is fluorescent intensity (photons per second) and $n$ is the number of bound Cy3-NGF. By using this correlation function and the obtained fluorescent intensities, the maximum number of Cy3-NGF molecules bound to low-affinity receptors on a single growth cone was estimated to be 713 , whereas the maximum number of Cy3NGF molecules bound to high-affinity receptors was calculated to be 202. By summing the maximum number of Cy3-NGF molecules bound to both high- and low-affinity receptors, $\sim 900$ 

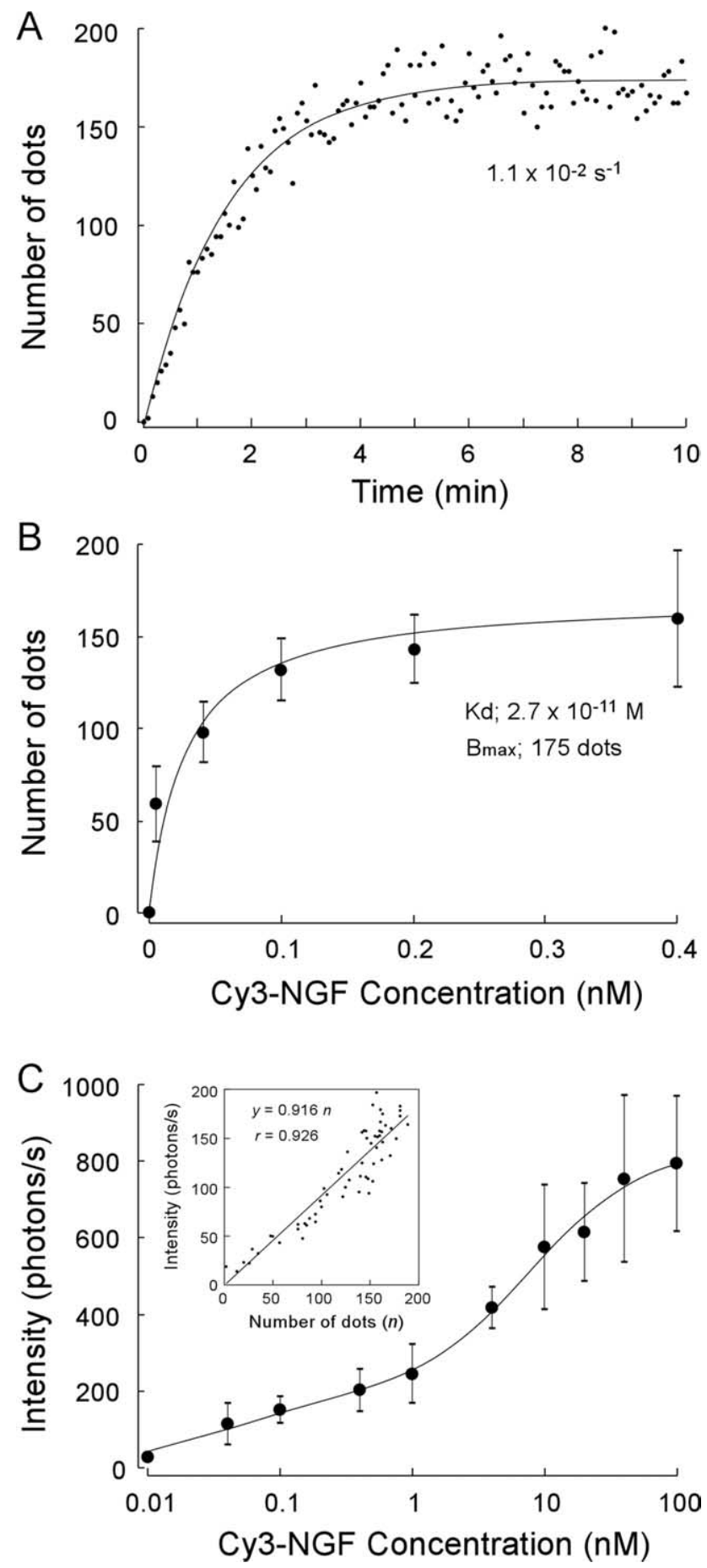

Figure 4. Local kinetics of the binding of NGF and the receptors on the growth cones. $A$, The increase in fluorescent dots bound onto a single growth cone after the application of $0.4 \mathrm{~nm}$ Cy3-NGF. The fitted single exponential curve is superimposed on the plot. $\boldsymbol{B}$, The averaged number of bound fluorescent dots on the growth cones as a function of various concentrations $(0,0.004,0.04,0.1,0.2$, and $0.4 \mathrm{~nm})$ of applied Cy3-NGF. The solution of the fitted curve, $y=$ $175 x /\left(2.7 \times 10^{-11}+x\right)$, is superimposed on the plot. Each point is a mean of eight values; the vertical bar at each point indicates the SD. $C$, The averaged fluorescent intensities of the growth cones were plotted against various concentrations of applied Cy3-NGF (from 0.01 to $100 \mathrm{~nm}$ ) in the culture medium. The solution of the curve with the best fit, $y=\left\{185 x /\left(3.5 \times 10^{-11}+\right.\right.$ $x)\}+\left\{653 x /\left(7.7 \times 10^{-9}+x\right)\right\}$, is superimposed on the plot. Each point is a mean of 5-15 values; the vertical bar at each point indicates the SD. C, Inset, Correlation plot of the number of fluorescent dots (horizontal axis) and the averaged fluorescent intensity (vertical axis) on the growth cone when $0.4 \mathrm{~nm}$ of Cy3-NGF was applied to the growth cone. A linear regression line, $y=0.916 n$, where $n$ is the number of bound fluorescent dots and $y$ is the averaged fluorescent intensity, is superimposed on the plot. molecules of Cy3-NGF were estimated to be bound to a single growth cone of DRG neurons when all NGF receptors were occupied by Cy3-NGF.

Two different modes of behavior of Cy3-NGF observed on the growth cone: lateral diffusion and one-directional rearward movement

Cy3-NGF gradually concentrated at the central region of the growth cone after binding to the receptors on growth cones (Fig. $1 A)$. To clarify the trafficking process that resulted in Cy3-NGF accumulating over the central region of growth cones, we monitored the behavior of a single Cy3-NGF molecule after it was bound to a receptor on the growth cone.

Most $(>99 \%)$ of the bound Cy3-NGF molecules on the growth cones were observed to be mobile. We found two different modes of movement in the behavior of Cy3-NGF on the growth cone. Approximately $83 \%(82.8 \pm 3.6 \%$; mean $\pm \mathrm{SD} ; n=$ 6 ) of the fluorescent dots in the lamellipodial region showed diffusive motion, as shown in the trajectories highlighted in Figure $5 A$ (supplemental movie 02, available at www.jneurosci.org as supplemental material). A linear regression line, $y=4 D_{1} t$, which was fit to the mean square displacement (MSD) plot of fluorescent dots $(n=16)$, provided the diffusion constant, $D_{1}=$ $0.31 \mu \mathrm{m}^{2} / \mathrm{s}$ (Fig. $5 C$ ). The rest, $\sim 17 \%(17 \pm 3.6 \%$; mean $\pm \mathrm{SD}$; $n=6$ ) of the fluorescent dots in the lamellipodial region, showed one-directional rearward movement toward the central region of the growth cone (Fig. 5B) (supplemental movie 03, available at www.jneurosci.org as supplemental material). The MSD plot (Fig. $5 D)$ of the fluorescent dots $(n=16)$ was fit by the equation $y=4 D_{2} t+(V t)^{2}$, where the mean velocity, $V$, was $3.6 \mu \mathrm{m} / \mathrm{min}$ and the diffusion constant, $D_{2}$, was $0.0096 \mu \mathrm{m}^{2} / \mathrm{s}$.

We compared the averaged fluorescent intensity of the diffusing dots and that of the dots showing one-directional rearward movement. Figure $5 E$ shows the histograms of fluorescent intensities obtained from the diffusing dots (top histogram) and dots showing one-directional movement (bottom histogram) in the lamellipodia of growth cones. By fitting Gaussian curves to the histograms, we obtained the central value of 1000 photons per second for the diffusing dots (indicated by a black arrowhead) and 1005 photons per second for the dots showing onedirectional movement (indicated by a white arrowhead). There was no significant difference between the fluorescent intensities of the dots of the two modes of behavior, diffusive and onedirectional movement, on the lamellipodial region of the growth cone. Moreover, both values were close to the fluorescent intensity of the single molecule of Cy3-NGF (Fig. $3 B, C$ ). The results indicated that these Cy3-NGF molecules existed as single molecules, regardless of their mode of behavior on the membrane of the growth cone.

Cy3-NGF-receptor complex shifted its mode of behavior from diffusion to one-directional rearward movement on the lamellipodial membrane

We observed the behavioral transition of a single Cy3-NGFreceptor complex from diffusive motion to one-directional rearward movement on the lamellipodial membrane. At first, growth cones had been incubated in a medium containing $0.4 \mathrm{~nm}$ Cy3NGF for $20 \mathrm{~min}$, and then they were transferred to a medium without Cy3-NGF to eliminate the possibility that Cy3-NGF started rearward movement immediately after its binding to the receptor. Figure 6 shows a DIC image $(A)$ and a fluorescent image $(B)$ of the growth cone after it was transferred to the medium without Cy3-NGF. There were several Cy3-NGF dots showing 
rearward movement in the lamellipodial region of the growth cone (Fig. $6 B$, white arrows). In Figure 6C, typical examples of Cy3-NGF dots (white arrowheads) that had started rearward movement were presented in three series of consecutive fluorescent micrographs (kymographs) of the area enclosed by white rectangles (1-3) in Figure $6 \mathrm{~A}$. These fluorescent dots originated from a population of diffusing dots and not from the surrounding medium, because there was no Cy3-NGF in the surrounding medium.

We estimated the rate of the transition from diffusive motion to one-directional movement by counting the number of fluorescent dots that had started and continued one-directional rearward movement in the lamellipodial area after the removal of Cy3-NGF from the surrounding medium (Fig. 6D). The rate constant of the transition was $6 \times 10^{-3} \mathrm{~s}^{-1}$, and in the steady state, $\sim 22 \%$ of the fluorescent dots on the lamellipodia region were estimated to belong to the population of onedirectional movement. This was consistent with the value $17 \pm 3.6 \%$, the percentage of Cy3-NGF molecules showing the rearward movement that was measured in the growth cone incubated in the medium with $0.4 \mathrm{~nm}$ Cy3-NGF for $20 \mathrm{~min}$.

\section{Actin-driven rearward trafficking of Cy3-NGF-receptor complexes toward the central region of the growth cone}

We expected that the rearward movement of Cy3-NGF-receptor complex was related to the rearward flow of the actin meshwork in the growth cones (Forscher and Smith, 1988). To clarify the relationship between the directional movement of the Cy3-NGFreceptor complex and the rearward flow of the actin meshwork beneath the membrane, the movement of Cy3-NGF and that of the actin meshwork stained by Alexa 647-phalloidin (final concentration, approximately several nanomolar) were observed simultaneously on the same growth cone (supplemental movie 04, available at www.jneurosci.org as supplemental material). The movement of Cy3-NGF during rearward traffic (Fig. 7Ac) and the rearward flow of actin (Fig. $7 A d$ ) are shown as kymographs acquired at exactly the same time at the location in the growth cone that is enclosed by white rectangles in Figure 7A, $a$ and $b$, respectively. Because Cy3-NGF and Alexa 647-phalloidin moved toward the central region of the growth cone with the same rates $(4.56 \mu \mathrm{m} / \mathrm{min}$ for Cy3-NGF and $4.54 \mu \mathrm{m} / \mathrm{min}$ for Alexa 647 phalloidin), Cy3-NGF and its receptor complex were suggested to be cross-linked to the actin meshwork. The rearward movement of each Cy3-NGF molecule was blocked by the application of latrunculin B, a potent and specific inhibitor of actin polymerization (Spector et al., 1983) (Fig. 7B). Before the addition of latrunculin $\mathrm{B}$, fluorescent dots moved toward the central region at an average velocity of $4.1 \pm 0.8 \mu \mathrm{m} / \mathrm{min}$ (mean $\pm \mathrm{SD} ; n=5$ ). Latrunculin B (200 nM) was applied to the growth cone at $t=1.2$ min. After the addition of latrunculin $B$, the velocity of the fluorescent dots suddenly decreased to the value of $0.7 \pm 1.4 \mu \mathrm{m} / \mathrm{min}$
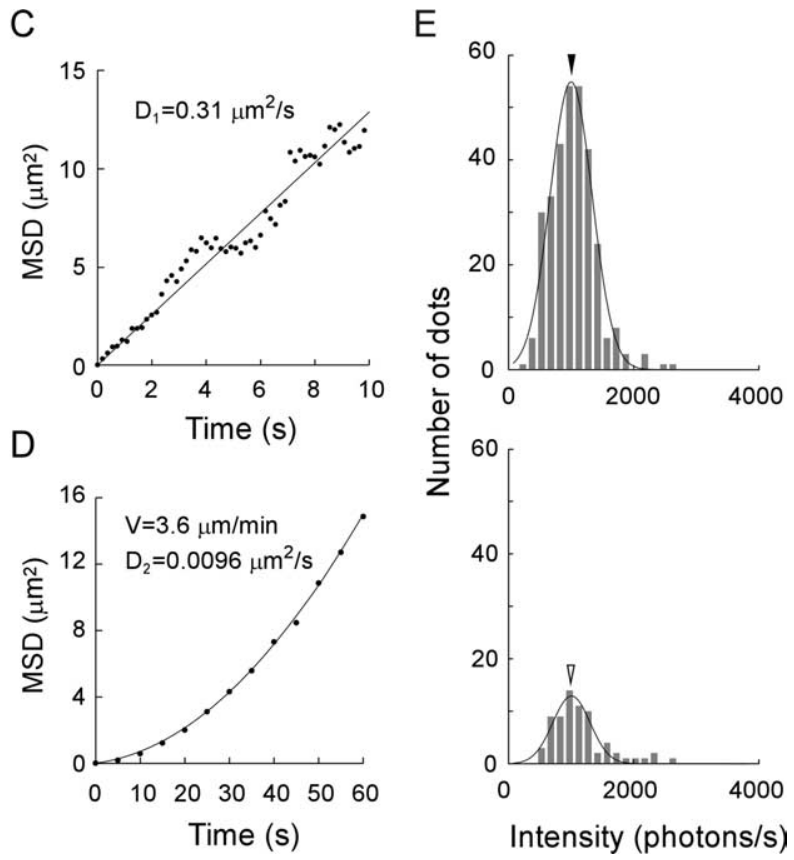

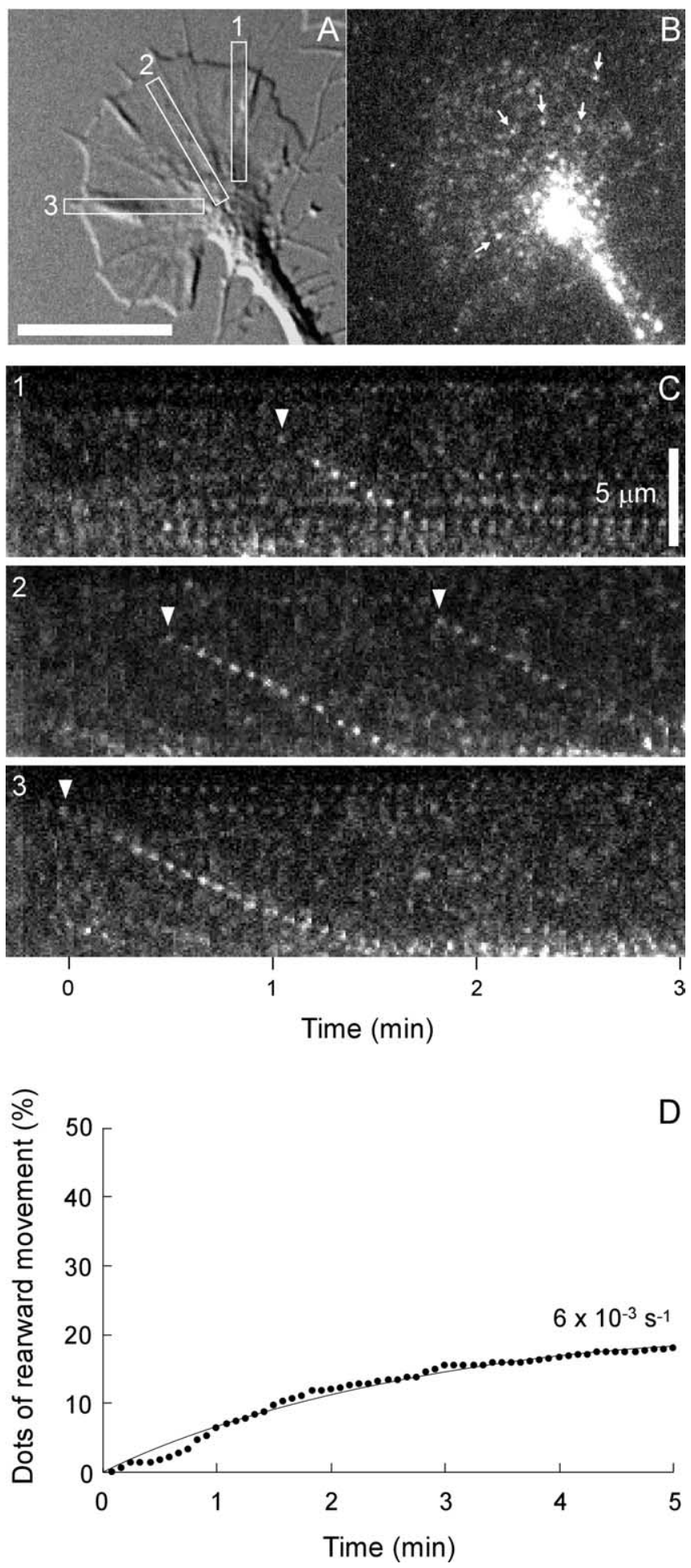

Figure 6. Behavioral transition of Cy3-NGF on the growth cone: from diffusive motion to one-directional rearward movement. ADIC image $(\boldsymbol{A})$ and a fluorescent image $(\boldsymbol{B})$ of the growth cone after the removal of $\mathrm{Cy} 3-\mathrm{NGF}$ from the surrounding medium. Fluorescent images were taken with an exposure time of $100 \mathrm{~ms}$ without binning. Scale bar, $10 \mu \mathrm{m}$. C, Consecutive fluorescent images (intervals, $5 \mathrm{~s}$ ) of the three areas (1-3) enclosed in the white rectangles in Figure $5 \mathrm{~A}$ were taken and aligned side by side from left to right. Downward progression of dots in the consecutive images corresponds to the one-directional movement toward the central region. White arrowheads indicate Cy3-NGF dots that have started one-directional rearward movement. $\boldsymbol{D}$, The time course of increase in the number of fluorescent dots that started and continued one-directional movement in the lamellipodial region. The numbers of fluorescent dots were averaged and normalized so that the initial number of diffusing dots in the lamellipodial region was $100 \%(n=4)$. the presence of $1 \mu \mathrm{M}$ latrunculin B (Fig. $7 D,+1 \mu \mathrm{M}$ latrunculin $B)$, although we did find a slow formation of clusters in the growth cone when observed for $>20 \mathrm{~min}$. These results indicated that Cy3-NGF-receptor complexes were transported toward the central region one by one accompanied by the rearward flow of the actin meshwork, and the resulting accumulation of Cy3-NGF at the central region was critical for the efficient uptake of Cy3NGF at the growth cone.

Endocytosis of Cy3-NGF-receptor complexes occurred during rearward trafficking at the vicinity of the central region of growth cones

At the distal tip of axons, NGF molecules are incorporated into membrane-bound vesicles by means of endocytosis (Claude et al., 1982). The simultaneous observation of DIC and fluorescent images of growth cones provided evidence that some Cy3-NGF clusters were already incorporated into vesicles (Fig. 1 A, B); however, the endocytotic processes of Cy3-NGF on the growth cone remained unclear.

To observe the endocytosis of Cy3-NGF, we removed Cy3NGF from trkA receptors on the surface of growth cones by decreasing the $\mathrm{pH}$ of the surrounding medium (Zapf-Colby and Olefsky, 1998). At first, DRG growth cones were incubated for 20 min in the medium of neutral $\mathrm{pH}$ with $0.4 \mathrm{nM}$ Cy3-NGF (Fig. $8 \mathrm{~A}$ ), and then the surrounding medium was completely replaced with the acidic medium of $\mathrm{pH}$ 4.3. It was evident that the fluorescent dots of Cy3-NGF on the lamellipodial region had disappeared entirely after the treatment with acidic medium (Fig. $8 \mathrm{~B}$ ). We found that even in the culture medium with an acidic $\mathrm{pH}$ as low as 4.3 , the growth cones kept their extended shape (Fig. $8 B$, DIC image). Growth cones resumed lamellipodial movement when the surrounding medium was returned to a medium of neutral $\mathrm{pH}$. The disappearance of the fluorescent dots from the lamellipodial region was not caused by the disruption or removal of lamellipodial membrane. Thus, after exposure to the acidic environment, most of the diffusing Cy3-NGF molecules in the lamellipodial region disappeared from the growth cone, whereas the clusters of Cy3-NGF in the central region remained. These results indicated that $\mathrm{Cy} 3-\mathrm{NGF}$-receptor clusters in the central region had been incorporated into vesicles in the cytoplasm, where they were isolated from the surrounding medium, whereas Cy3-NGF-receptor molecules in the lamellipodial region were still exposed to the surrounding medium, allowing them to be influenced by the acidic $\mathrm{pH}$ of the culture medium.

We wanted to determine whether the Cy3-NGF-receptor complexes during rearward traffic were still exposed to the surrounding medium or already internalized. We monitored the behavior of Cy3-NGF molecules showing rearward movement before and after treatment with acidic medium. Approximately $24 \%$ of the molecules disappeared after the acidification of the surrounding medium. The rest $(76 \%)$ of the molecules still remained associated with the growth cones after acidification. Typical examples of (1) acid-labile and (2) acid-persistent Cy3-NGF after acidification of the surrounding medium are shown in Figure $8 C$, top and bottom kymographs, respectively. Interestingly, there was a correlation between the fate of Cy3-NGF (liberated or retained) and the location of the molecules when the acidic medium was applied (Fig. 8D). The persistent molecules tended to be located at the vicinity of the central region (i.e., the transition region) when the acidic medium was applied. In contrast, most of the acid-labile molecules were in the middle of the lamellipo- 
dium, at some distance from the central region when the $\mathrm{pH}$ of the surrounding medium was changed. These results suggested that Cy3-NGF-receptor complexes had been incorporated into the cytoplasm during the one-directional movement, when the molecules were about to reach the central region of the growth cone.

\section{Discussion}

Single-molecule imaging of

fluorescently labeled NGF on the dorsal root ganglion growth cone

Here we have observed the binding, trafficking, and endocytosis of the single molecules of fluorescent NGF on the growth cones of dorsal root ganglion neurons. The use of fluorescently labeled NGF was first reported by Levi et al. (1980) to investigate the mobility and clustering of NGF on NGF-responsive cells. They observed the formation of rhodamine-NGF clusters on the cell body of sensory cells after the temperature of incubation was shifted from $4^{\circ}$ to $37^{\circ} \mathrm{C}$; however, relatively high background fluorescence caused by the high concentration of applied fluorescent NGF (10 nM) probably obscured the observation of the clustering process of NGF. We used a modified fiber-optics epiillumination system that allowed us to see the single molecules of Cy3-NGF over the whole surface as well as inside growth cones. We did not use evanescent wave illumination (Axelrod, 1981) as had been used for fluorescent single-molecule imaging (Funatsu et al., 1995). Because the light reached only $\sim 100 \mathrm{~nm}$ from the surface of the glass coverslip, evanescent excitation light was not likely to illuminate all of the molecules of Cy3-NGF on the apical and basal sides as well as inside the growth cone, which has a thickness of several micrometers.

\section{Actin-driven rearward flow facilitates the uptake of NGF at the growth cone}

Observation of single molecules of NGF on the growth cone revealed that each molecule of the NGF-receptor complex began one-directional movement toward the central region once it was captured by the rearward flow of the actin meshwork. A potent and specific inhibitor of actin polymerization, latrunculin $\mathrm{B}$ blocked this trafficking of Cy3-NGF and the subsequent accumulation and clustering of $\mathrm{Cy} 3-\mathrm{NGF}$ at the central region of the growth cone. The rearward flow of actin plays a key role in the progress of the growth cone (Lin and Forscher, 1995). Here we have demonstrated that this rearward flow of actin was also indispensable for the effective uptake of NGF at the growth cone. The trafficking of Cy3-NGF was very sensitive to the presence of latrunculin B: as low as $200 \mathrm{~nm}$ latrunculin B could completely block the rearward movement of Cy3-NGF. In the presence of $200 \mathrm{~nm}$ latrunculin $\mathrm{B}$, we could not observe the withdrawal of cytoplasm from the distal margin of the growth cone (Forscher
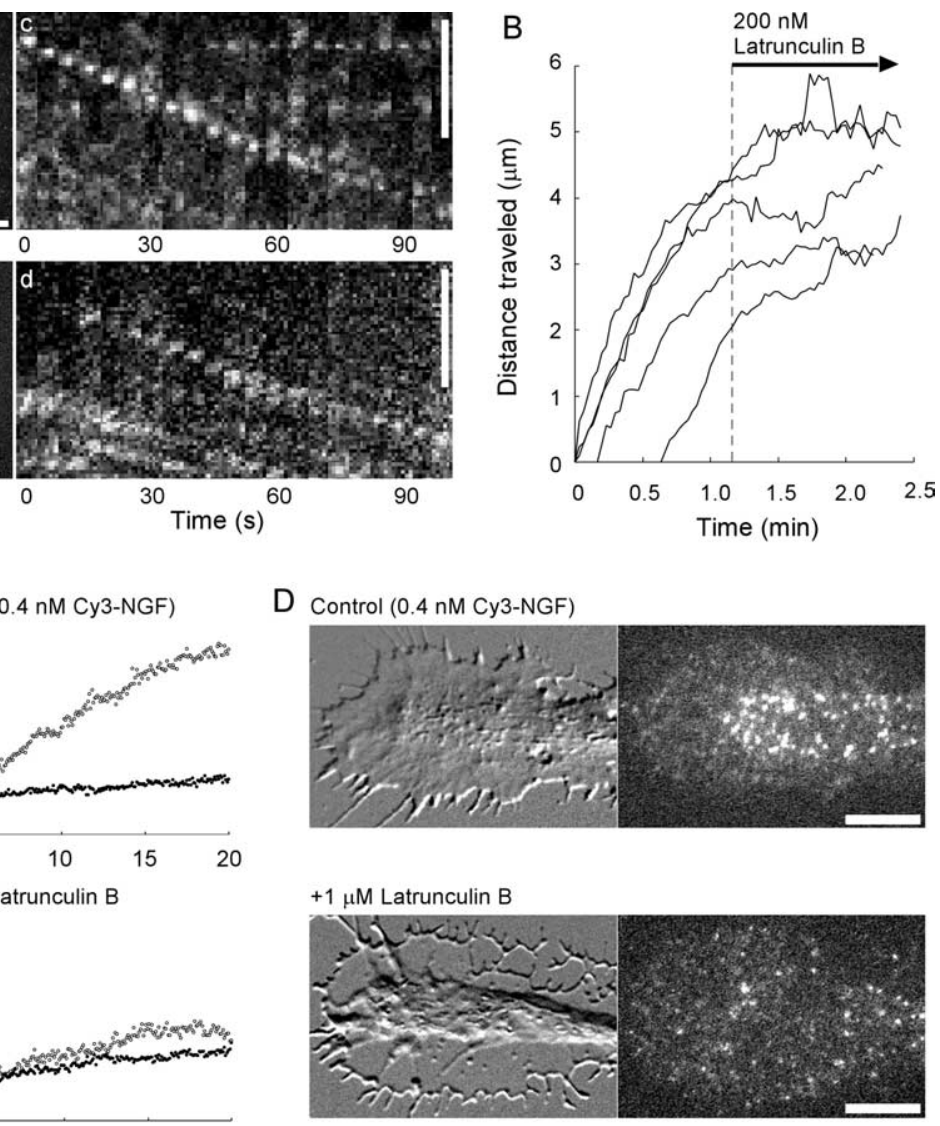

Figure 7. Actin-driven trafficking of Cy3-NGF toward the central region of the growth cone. $A$, Simultaneous observation of y3-NGF trafficking $(\boldsymbol{a}, \boldsymbol{c})$ and rearward flow of actin stained by Alexa 647-phalloidin $(\boldsymbol{b}, \boldsymbol{d})$. In $\boldsymbol{c}$ and $\boldsymbol{d}$, consecutive fluorescent

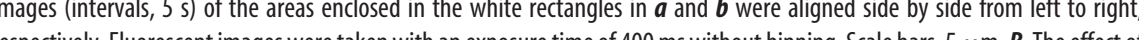
$200 \mathrm{~nm}$ latrunculin B on the rearward movement of single Cy3-NGF-receptor complexes. The traveled distances of five fluorescent dots on a single growth cone were plotted against time; $200 \mathrm{~nm}$ latrunculin B was added at $1.2 \mathrm{~min}$. C, Changes in fluorescent intensities at the central region $(\bigcirc)$ and at the lamellipodial region $(O)$ of the growth cone after the application of $0.4 \mathrm{~nm} C \mathrm{Cy}-\mathrm{NGF}$ ansence (top plots) and presence (bottom plots) of $1 \mu \mathrm{m}$ latrunculin B. D, DIC images (left) and fluorescent images (right) of latrunculin B (final concentration, $1 \mu \mathrm{m}$ ) was applied to the growth cone shown in the bottom photographs. Fluorescent images were taken with an exposure time of $80 \mathrm{~ms}$ without binning. Scale bars, $10 \mu \mathrm{m}$.

and Smith, 1988). The driving force of rearward actin flow has been shown to be caused by myosin motors located at the transition region of the growth cones (Lin et al., 1996); however, low concentrations of latrunculin B might stop the rearward flow of actin by inhibiting the polymerization of actin at its plus end without causing the loss of the linkage between the end of the actin filament and the stable extracellular substrate.

We also observed the transition of the behavior of the Cy3NGF-receptor complex from lateral diffusion to a onedirectional rearward movement (Fig. 6). The number of Cy3NGF involved in rearward movement had a maximum limit (i.e., $\sim 20 \%$ of the total bound Cy3-NGF showed rearward movement under steady-state conditions). Because it was very rare to observe Cy3-NGF molecules released from the rearward flow once they had started one-directional movement, the maximum number of Cy3-NGF molecules involved in rearward movement was likely to be determined by the number of diffusing Cy3-NGF molecules that were capable of interacting (directly or indirectly) with the actin meshwork. A modification of NGF receptors such 

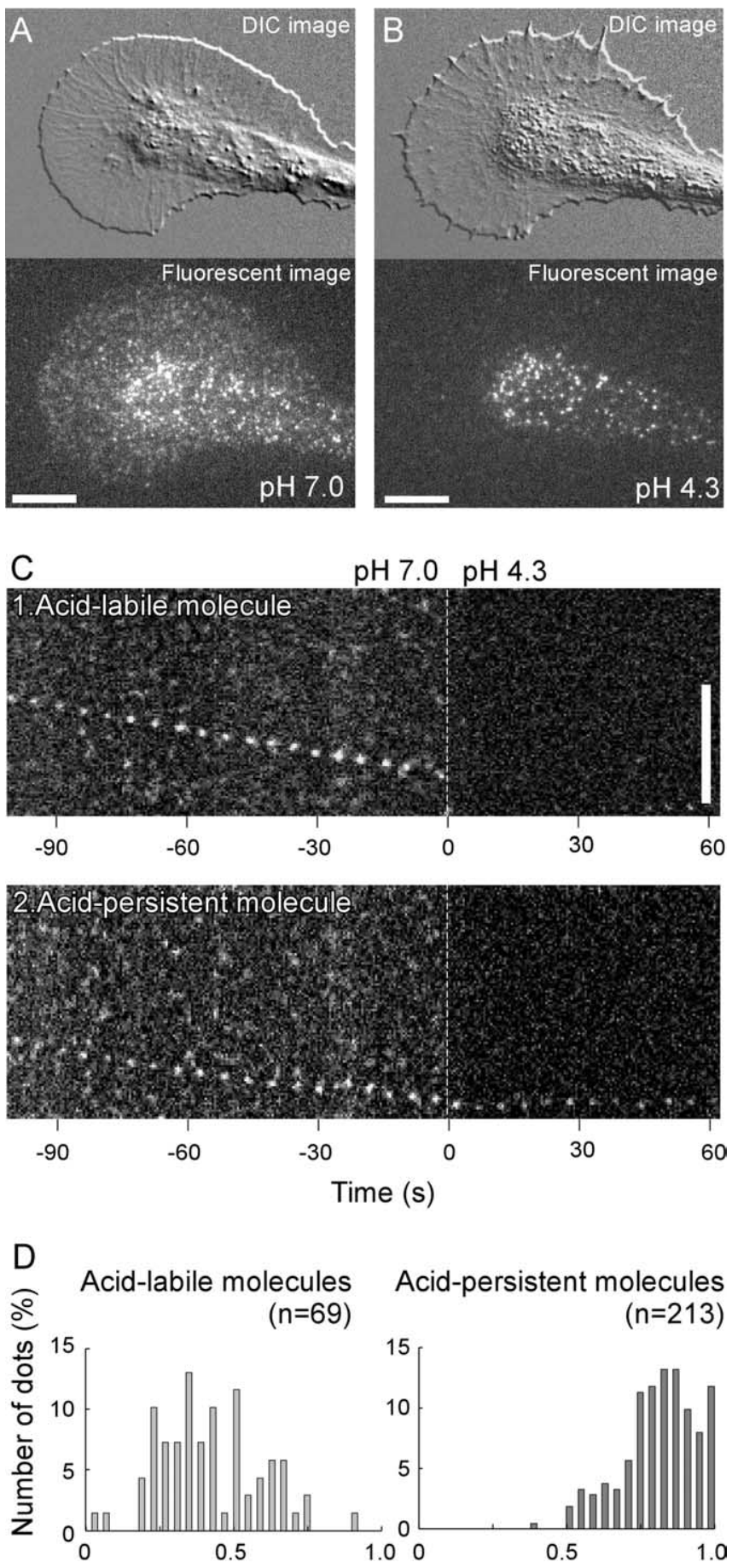

\section{Relative distance from leading edge}

Figure 8. Observation of endocytosed Cy3-NGF in the DRG growth cones. $A, B$, DIC images and fluorescent images of the growth cone before $(\boldsymbol{A})$ and after $(\boldsymbol{B})$ the acidification of surrounding medium. Fluorescent images were taken with an exposure time of $50 \mathrm{~ms}$ without binning. Scale bars, $10 \mu \mathrm{m}$. C, Consecutive fluorescent images of single Cy3-NGF molecule on the rearward traffic before and after the acidification of surrounding medium. Examples of (1) acidlabile molecules and that of (2) acid-persistent molecules are shown. Fluorescent images were taken at intervals of 5 s and aligned from left to right. The vertical white broken line indicates the time of acidification of the culture medium $(t=0)$. Scale bar, $10 \mu \mathrm{m}$. $\boldsymbol{D}$, Histograms of the location of acid-labile (left) and acid-persistent (right) fluorescent dots that were exhibiting one-directional movement when an acidic culture medium was applied. The locations of fluorescent dots on the rearward flow were expressed as normalized distances from the leading edge of the lamellipodium so that the leading edge of the lamellipodium was 0 and the margin of the central region was 1.0. The numbers of acid-labile and persistent dots were expressed as percentages of the total number of dots observed.
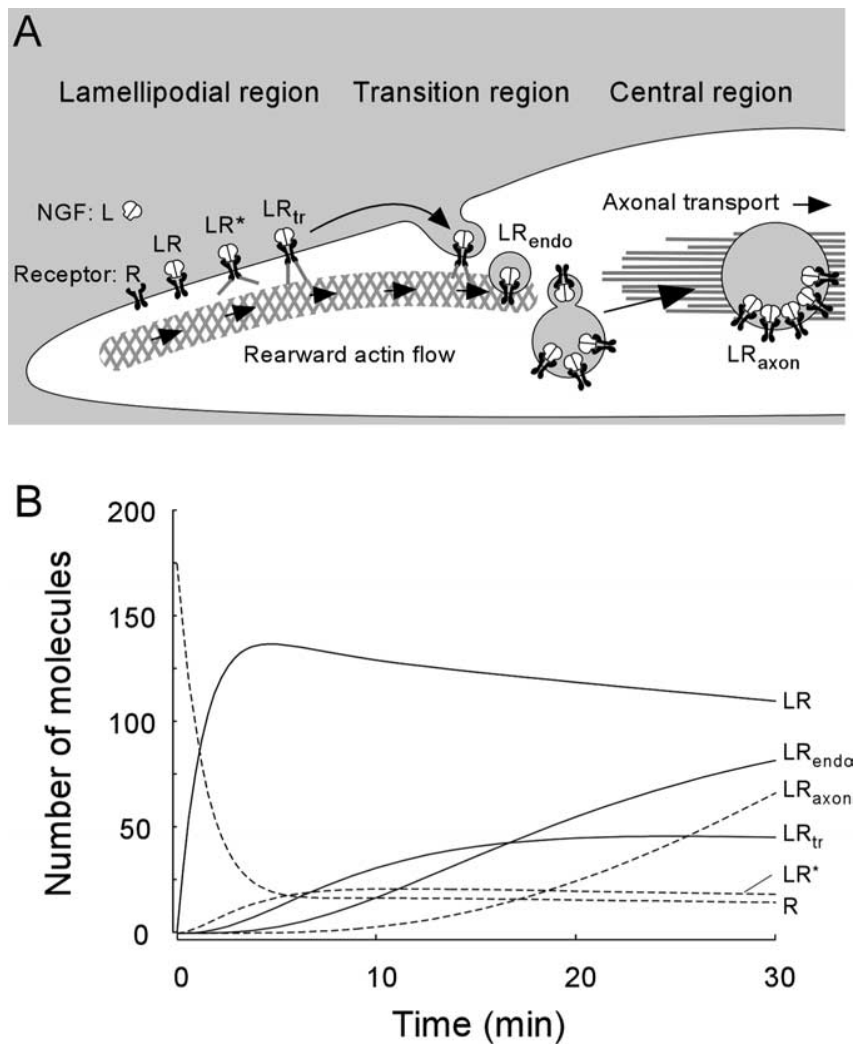

Figure 9. The model of NGF binding, trafficking, and uptake at the dorsal root ganglion growth cone. $A$, Schematic diagram showing the side view of the dissected growth cone during NGF uptake based on our observation of Cy3-NGF. $B$, Simulated time courses of the numbers of $L R, L R_{\mathrm{tr}}$ and $L R_{\text {endo }}$ (solid lines) and $R, L R^{*}$, and $L R_{\text {axon }}$ (broken lines) in a single growth cone based on the diagram in Figure $9 A$ and Scheme 1 in Discussion. The following constants were used for the calculation: concentration of Cy3-NGF, $4 \times 10^{-10} \mathrm{M}$; number of free receptors at $t=0,175 ; k_{\text {on }}=2.8 \times 10^{7} \mathrm{M}^{-1} \mathrm{~s}^{-1}$ and $k_{\mathrm{tr}}=6 \times 10^{-3} \mathrm{~s}^{-1} \cdot k_{\text {off }}=6 \times 10^{-4} \mathrm{~s}^{-1}$ was estimated from the $k_{\text {on }}$ and the dissociation constant, $k_{\mathrm{d}}$. The rate of insertion of new receptors to the surface membrane was assumed to be proportional to the concentration of activated ligand-receptor complexes, $L R^{*}$, with the rate constant, $k_{\mathrm{s}}=5 \times 10^{-3} \mathrm{~s}^{-1}$. The value for $k_{\text {axon }}, 1 \times 10^{-3} s^{-1}$, was obtained preliminarily, and the values for $k_{\text {act }}=1 \times 10^{-3} \mathrm{~s}^{-1}$, $k_{\text {inact }}=1 \times 10^{-4} \mathrm{~s}^{-1}$, and $k_{\text {endo }}=2.5 \times 10^{-3} \mathrm{~s}^{-1}$ were determined by trial and error until the simulated time courses matched the experimentally obtained time courses of $L R$, $L R_{\text {tr }}$ and $L R_{\text {endo }}$.

as phosphorylation-dephosphorylation may allow diffusing ligand-receptor complexes to interact with the actin meshwork.

\section{The role of diffusing NGF-receptor complexes in signaling} motile responses of the growth cone

NGF-receptor complexes showed lateral diffusion in the membrane of growth cones before they were transported toward the central region (Fig. $5 A$ ). We found that $\sim 40$ molecules of these diffusive NGF-receptor complexes could evoke the lamellipodial expansion of growth cones (Figs. 2D, 4A). The estimated number of high-affinity receptors on a single growth cone was 175 and that of low-affinity receptors was 713 . Assuming that $\sim 900$ binding sites on a single growth cone are capable of interacting with NGF, $<5 \%$ of the total binding sites need to be occupied to initiate the full motile response of the growth cone. The role of so many unoccupied receptors during signal transduction-amplification remains unclear. The ratio of the number of high-affinity receptors to low-affinity receptors on a growth cone was threefold to fourfold higher than that on the whole cell membrane of sensory neurons (Sutter et al., 1979; Vale and Shooter, 1985). 
This difference in composition of high- and low-affinity NGF receptors may indicate a difference in sensitivity to NGF and/or the different signal transduction pathways between the growth cone and the cell body.

\section{Endocytosis of NGF molecules during their rearward trafficking on the growth cone}

Experiments of rapid acidification of the surrounding medium suggested that the attachment of diffusing Cy3-NGF to the lamellipodial membrane can be disrupted by acidifying the surrounding medium, whereas the clusters of Cy3-NGF in the central region were unaffected because they had been incorporated into intracellular vesicles (Fig. 8 B). Cy3-NGF-receptor complexes are thought to be internalized during rearward trafficking at the transition region of the growth cone (Fig. 8C,D). Because Cy3-NGF molecules on the rearward traffic had been determined to be single molecules (Figs. $3 B, C, 5 E$ ), these observations led to the idea that each NGF-receptor complex undergoing rearward trafficking could be endocytosed one by one without first forming a cluster with neighboring complexes. Receptor-mediated endocytosis is thought to occur after ligand-receptor complexes form clusters together with adapters and clathrin molecules (Santini and Keen, 1996), and several studies have reported the formation of clathrin-coated vesicles in the NGF-responsive cells after NGF is bound to trkA and/or p75 receptor molecules (Howe et al., 2001; Bronfman et al., 2003). At present, it is unclear whether the endocytosed Cy3-NGF that we observed at the transition region is internalized through a clathrin-dependent pathway. A clathrin-independent pathway mediated by a pinocytic chaperone protein "pincher" (Shao et al., 2002) may work on the endocytosis of NGF at the transition region of the growth cone.

\section{The model of NGF trafficking and uptake at the growth cone}

Based on our observations and assumptions, the kinetic processes of NGF uptake at the growth cone are formulated as follows:

$$
L+R \underset{k_{\text {off }}}{\stackrel{k_{\text {on }}}{\rightleftarrows}} L R \underset{k_{\text {inact }}}{\stackrel{k_{\text {act }}}{\rightleftarrows}} L R^{*} \stackrel{k_{\text {tr }}}{\longrightarrow} L R_{\text {tr }} \stackrel{k_{\text {endo }}}{\longrightarrow} L R_{\text {endo }} \stackrel{k_{\text {axon }}}{\longrightarrow} L R_{\text {axon }},
$$

(Scheme 1)

where $L$ is the free Cy3-NGF, $R$ is the free receptor, $L R$ is the diffusing Cy3-NGF-receptor complex incapable of interacting with actin, $L R^{\star}$ is the diffusing Cy3-NGF-receptor complex capable of interacting with actin, $L R_{\mathrm{tr}}$ is the Cy3-NGF-receptor complex during rearward flow, $L R_{\text {endo }}$ is the endocytosed complex at the transition region, and $L R_{\text {axon }}$ is the complex during retrograde transport along the axon (Fig. 9A). $k_{\text {on }}, k_{\text {off }}, k_{\text {act }}, k_{\text {inact }}$, $k_{\text {tr }}, k_{\text {endo }}$, and $k_{\text {axon }}$ are the rate constants for the reactions indicated as arrows in Scheme 1. We simulated the kinetic processes of NGF binding, trafficking, and endocytosis on a single growth cone based on the constants that we obtained and by making some assumptions, including the idea that the rate of insertion of new and/or recycled receptors to the surface membrane was proportional to the number of activated ligand-receptor complexes, $L R^{\star}$. The simulated time courses of change in the numbers of $L R$, $L R_{\text {tr }}$, and $L R_{\text {endo }}$ virtually mimicked those that we actually observed on a single growth cone (Fig. $9 B$ ).

Fluorescent single-molecule imaging has been used to see in real time the interactions between ligands and receptors on live cells (Sako et al., 2000; Ueda et al., 2001). Together with data on the activation of intracellular signaling molecules and/or with accompanying cellular responses, single-molecule imaging of the binding of ligands will allow us to analyze the quantal events of signal transduction and amplification within cells.

\section{References}

Axelrod D (1981) Cell-substrate contacts illuminated by total internal reflection fluorescence. J Cell Biol 89:141-145.

Bronfman FC, Tcherpakov M, Jovin TM, Fainzilber M (2003) Ligandinduced internalization of the 75 neurotrophin receptor: a slow route to the signaling endosome. J Neurosci 23:3209-3220.

Campenot RB (1977) Local control of neurite development by nerve growth factor. Proc Natl Acad Sci USA 74:4516-4519.

Chao MV, Bothwell MA, Ross AH, Koprowski H, Lanahan AA, Buck CR, Sehgal A (1986) Gene transfer and molecular cloning of the human NGF receptor. Science 232:518-521.

Claude P, Hawrot E, Dunis DA, Campenot RB (1982) Binding, internalization, and retrograde transport of ${ }^{125} \mathrm{I}$-nerve growth factor in cultured rat sympathetic neurons. J Neurosci 2:431-442.

Connolly JL, Seeley PJ, Greene LA (1987) Rapid regulation of neuronal growth cone shape and surface morphology by nerve growth factor. Neurochem Res 12:861-868.

Delcroix JD, Valletta JS, Wu C, Hunt SJ, Kowal AS, Mobley WC (2003) NGF signaling in sensory neurons: evidence that early endosomes carry NGF retrograde signals. Neuron 39:69-84.

Forscher P, Smith SJ (1988) Actions of cytochalasins on the organization of actin filaments and microtubules in a neuronal growth cone. J Cell Biol 107:1505-1516.

Funatsu T, Harada Y, Tokunaga M, Saito K, Yanagida T (1995) Imaging of single fluorescent molecules and individual ATP turnovers by single myosin molecules in aqueous solution. Nature 374:555-559.

Gatzinsky KP, Haugland RP, Thrasivoulou C, Orike N, Budi-Santoso AW, Cowen T (2001) p75 and TrkA receptors are both required for uptake of NGF in adult sympathetic neurons: use of a novel fluorescent NGF conjugate. Brain Res 920:226-238.

Grimes ML, Beattie E, Mobley WC (1997) A signaling organelle containing the nerve growth factor-activated receptor tyrosine kinase, TrkA. Proc Natl Acad Sci USA 94:9909-9914.

Hempstead BL, Martin-Zanca D, Kaplan DR, Parada LF, Chao MV (1991) High-affinity NGF binding requires coexpression of the Trk protooncogene and the low-affinity NGF receptor. Nature 350:678-683.

Hendry IA, Stockel K, Thoenen H, Iversen LL (1974) The retrograde axonal transport of nerve growth factor. Brain Res 68:103-121.

Herrup K, Shooter EM (1973) Properties of the $\beta$ nerve growth factor receptor of avian dorsal root ganglia. Proc Natl Acad Sci USA 70:3884-3888.

Howe CL, Valletta JS, Rusnak AS, Mobley WC (2001) NGF signaling from clathrin-coated vesicles: evidence that signaling endosomes serve as a platform for the Ras-MAPK pathway. Neuron 32:801-814.

Kam Z, Jones MO, Chen H, Agard DA, Sedat JW (1993) Design and construction of an optimal illumination system for quantitative wide-field multi-dimensional microscopy. Bioimaging 1:71-81.

Kaplan DR, Hempstead BL, Martin-Zanca D, Chao MV, Parada LF (1991) The Trk proto-oncogene product: a signal transducing receptor for nerve growth factor. Science 252:554-558.

Kasaian MT, Jacobberger JW, Neet KE (1994) Flow cytometric analysis of fluorescein-labeled nerve growth factor binding to A875 human melanoma cells. Exp Cell Res 210:77-85.

Kinosita K, Jr., Itoh H, Ishiwata S, Hirano K, Nishizaka T, Hayakawa T (1991) Dual-view microscopy with a single camera: real-time imaging of molecular orientations and calcium. J Cell Biol 115:67-73.

Korsching S, Thoenen H (1983) Nerve growth factor in sympathetic ganglia and corresponding target organs of the rat: correlation with density of sympathetic innervation. Proc Natl Acad Sci USA 80:3513-3516.

Lalli G, Schiavo G (2002) Analysis of retrograde transport in motor neurons reveals common endocytic carriers for tetanus toxin and neurotrophin receptor p75NTR. J Cell Biol 156:233-239.

Levi A, Shechter Y, Neufeld EJ, Schlessinger J (1980) Mobility, clustering, and transport of nerve growth factor in embryonal sensory cells and in a sympathetic neuronal cell line. Proc Natl Acad Sci USA 77:3469-3473.

Levi-Montalcini R (1982) Developmental neurobiology and the natural history of nerve growth factor. Annu Rev Neurosci 5:341-362. 
Lin CH, Forscher P (1995) Growth cone advance is inversely proportional to retrograde F-actin flow. Neuron 14:763-771.

Lin CH, Espreafico EM, Mooseker MS, Forscher P (1996) Myosin drives retrograde F-actin flow in neuronal growth cones. Neuron 16:769-782.

MacInnis BL, Campenot RB (2002) Retrograde support of neuronal survival without retrograde transport of nerve growth factor. Science 295:1536-1539.

Nakai J, Kawasaki Y (1959) Studies on the mechanism determining the course of nerve fibers in tissue culture. I. The reaction of the growth cone to various obstructions. Z Zellforsch Mikrosk Anat 51:108-122.

Sako Y, Minoghchi S, Yanagida T (2000) Single-molecule imaging of EGFR signaling on the surface of living cells. Nat Cell Biol 2:168-172.

Santini F, Keen JH (1996) Endocytosis of activated receptors and clathrincoated pit formation: deciphering the chicken or egg relationship. J Cell Biol 132:1025-1036.

Shao Y, Akmentin W, Toledo-Aral JJ, Rosenbaum J, Valdez G, Cabot JB, Hilbush BS, Halegoua S (2002) Pincher, a pinocytic chaperone for nerve growth factor/TrkA signaling endosomes. J Cell Biol 157:679-691.

Spector I, Shochet NR, Kashman Y, Groweiss A (1983) Latrunculins: novel marine toxins that disrupt microfilament organization in cultured cells Science 219:493-495.

Sutter A, Riopelle RJ, Harris-Warrick RM, Shooter EM (1979) Nerve growth factor receptors. Characterization of two distinct classes of binding sites on chick embryo sensory ganglia cells. J Biol Chem 254:5972-5982.

Tessier-Lavigne M, Goodman CS (1996) The molecular biology of axon guidance. Science 274:1123-1133.

Ueda M, Sako Y, Tanaka T, Devreotes P, Yanagida T (2001) Single-molecule analysis of chemotactic signaling in Dictyostelium cells. Science 294:864-867.

Vale RD, Shooter EM (1985) Assaying binding of nerve growth factor to cell surface receptors. Methods Enzymol 109:21-39.

Zapf-Colby A, Olefsky JM (1998) Nerve growth factor processing and trafficking events following TrkA-mediated endocytosis. Endocrinology 139:3232-3240.

Zhou FQ, Zhou J, Dedhar S, Wu YH, Snider WD (2004) NGF-induced axon growth is mediated by localized inactivation of GSK-3beta and functions of the microtubule plus end binding protein APC. Neuron 42:897-912. 